\title{
Fixed drug eruptions to ciprofloxacin - a case report
}

\author{
Rama R. Bhosale ${ }^{\text {a,* }}$, Abhishek V. Patil ${ }^{\text {b }}$
}

${ }^{a}$ Department of Pharmacology, R.C.S.M. Govt. Medical College, Kolhapur-416002, Maharashtra, India,

${ }^{\mathrm{b}}$ Department of Skin and VD, R.C.S.M. Govt. Medical

College, Kolhapur-416002, Maharashtra, India

Received: 18 October 2012

Revised: 19 November 2012

Accepted: 23 November 2012

\section{*Correspondence to:}

Dr. Rama R. Bhosale,

Email: bhosale.rama@rediffmail.com

\begin{abstract}
Fixed drug eruptions (FDE) are common adverse drug reactions and they recur at the same site with each exposure to a particular drug. Drugs inducing FDE are usually those taken intermittently. Most common drugs causing fixed drug eruptions are antibiotics and analgesics. Here, we report a case of FDE to ciprofloxacin which was used in treatment of upper respiratory tract infection.
\end{abstract}

Keywords: Adverse drug reaction, ciprofloxacin, fixed drug eruption

the past due to some medication. On cutaneous examination, well-defined erythematous plaques of varied sizes were present over the lower limbs and inguinal region (Figure 1). No involvement of the genitalia and face were present. Routine blood investigations were normal. The causality assessment was carried out using the Naranjo ADR probability scale. ${ }^{3}$ A diagnosis of FDE to ciprofloxacin was made and the patient was told to stop the offending agent. The therapy was started with azithromycin 500mg daily for five days for respiratory tract infection and antihistamines, topical steroids for skin lesion. There was complete recovery of the patient from respiratory tract infection and skin lesion as well within seven days.

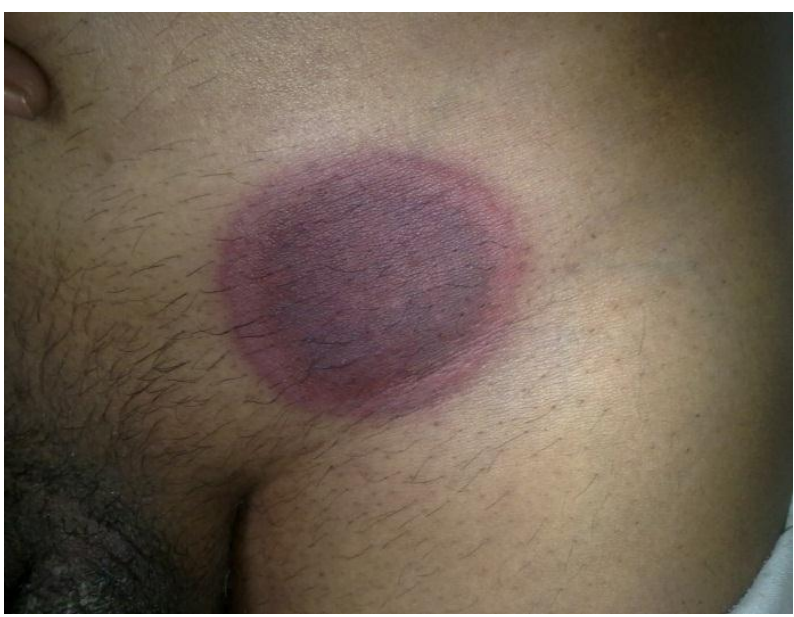

Figure 1: Plaque with erythematous border over the inguinal region.$$
\text { inginal region. }
$$

A 35-year-old male presented to the skin OPD with a history of rash since one day. These rashes were associated with burning and itching. History of drug intake (tab ciprofloxacin $500 \mathrm{mg}$ ) one day back was followed by itching with rash in next morning. Seven days prior to this, he had presented to a general practitioner with symptoms of running nose, dry cough and mild fever. Although no diagnosis was found in the documents provided by the patient, he was prescribed antihistaminic and paracetamol combination. There was no improvement by this therapy. Diagnosis was made as upper respiratory tract infection by another physician and continued therapy by adding ciprofloxacin. There was no history of any other medications. After 8-12 hours, he developed erythematous maculopapular rash in the inguinal region. There was a history of similar lesions in 


\section{DISCUSSION}

Adverse drug reactions (ADRs) are a major hazard of modern medicine. Among all these, cutaneous ADRs are an important clinical entity that can endanger the life of the patient. FDE is a distinctive drug-induced dermatological disorder with a characteristic recurrence at the same sites of the skin or mucous membrane after repeated exposure to the causative drug. FDE is believed to be a lymphocyte CD8-mediated reaction in which drug may induce local reactivation of memory $\mathrm{T}$ cell lymphocytes localized in epidermal and dermal tissues. ${ }^{4}$ The most common drugs causing FDE are antibiotics followed by non-steroidal anti-inflammatory drugs. ${ }^{2}$

Ciprofloxacin is one of the most common antibiotics used in practice. It is a fluorinated quinolone having broad antimicrobial activity against both gram positive and gram negative organisms, excellent tissue penetration, twice a day dosage schedule and is effective after oral as well as parenteral administration. Side effects of ciprofloxacin are relatively few and development of resistance by microbes is also rare. It is used in infections of urinary tract, respiratory tract, bones and soft tissues. A few cases of ciprofloxacin-induced photosensitivity, hypersensitivity, anaphylaxis, vasculitis, erythema multiforme or toxic epidermal necrolysis have been reported so far. ${ }^{5}$ FDE to ciprofloxacin is rarely reported.

Causal relationship between the drug and the reaction is assessed depending on the lag period between the start of the drug and the appearance of the reaction. In the present case report, the patient presented with FDE immediately after oral administration of ciprofloxacin and completely cured after stopping the drug. According to the Naranjo ADR probability scale $($ score $=8),{ }^{3}$ this $\mathrm{ADR}$ is categorized as a 'probable' reaction to the drug.

Therefore, this rare case is presented to create awareness about the various side effects associated with this type of very commonly prescribed antibiotic.

\section{REFERENCES}

1. Kaur I, Singh J. Cutaneous drug reaction with intravenous ceftriaxone. Indian $\mathbf{J}$ Pharmacol 2009;41:284-5.

2. Chatterjee S, Ghosh AP, Barbhuiya J, Dey SK. Adverse cutaneous drug reactions: A one year survey at a dermatology outpatient clinic of a tertiary care hospital. Indian J Pharmacol 2006;38:429-31.

3. Naranjo CA, Busto U, Sellers EM, Sandor P, Ruiz I, Roberts EA, et al. A method for estimating the probability of adverse drug reactions. Clin Pharmacol Ther 1981;30:239-45.

4. Shiohara T, Mizukawa Y. Fixed drug eruption: A disease mediated by self-inflicted responses of intraepidermal T cells. Eur J Dermatol 2007;17:2018.

5. Jeevanagi SR, Manjunath S, Wali VK. A case of ciprofloxacin-induced erythema multiforme. Indian J Pharmacol 2008;40:45-6.

doi: 10.5455/2319-2003.ijbcp004112

Cite this article as: Bhosale RR, Patil AV. Fixed drug eruptions to ciprofloxacin - a case report. Int J Basic Clin Pharmacol 2012;1:221-2. 